\title{
CULTURA E SOCIEDADE NO SISTEMA CULINÁRIO DA MANDIOCA NO BRASIL
}

\author{
CULTURE AND SOCIETY IN THECULINARYSYSTEM \\ OF MANIOC IN BRAZIL*
}

\author{
Ricardo Frota de Albuquerque Maranhão ${ }^{1}$, Senia Regina Bastos ${ }^{2}$ \\ e Marilia Malzoni MarChI ${ }^{3}$
}

Recebido em: 06/02/2015

Aprovado em: 27/11/2015

\section{RESUMO}

Este estudo foi elaborado a partir da premissa de que as escolhas alimentares dos grupos sociais são fatos culturais (VALERI, 1989) e de que a cozinha ou culinária permeia a vida cotidiana e os costumes, no que diz respeito tanto aos ingredientes quanto às receitas, às formas de preparo e aos utensílios utilizados (REVEL, 1996). Este artigo apresenta elementos culturais e sociais embasados na história e na arqueologia e, ao mesmo tempo, revela a existência de um verdadeiro sistema tecnológico de produção - o sistema culinário da mandioca. Esse sistema foi analisado sob quatro perspectivas: o ingrediente ou a matéria-prima, isto é, a mandioca do ponto de vista físico; a explicação de sua origem e sua prática social ou cultura; a técnica e os seus usos, que vão do plantio à obtenção dos produtos do sistema - estas três, metodologicamente informadas pela antropologia e pela história, precedem a quarta perspectiva, em que uma análise formal do conteúdo de uma obra de arte histórica permite enfatizar a importância dessa raiz na vida e na cultura dos povos indígenas no Brasil.

Palavras-chave: Cultura da mandioca; Sistema culinário; Subprodutos da mandioca; Cultura indígena.

\begin{abstract}
This researchwas drawn from the premise that the food choices of social groups are cultural facts (VALERI, 1989). And the premise that culinary permeates everyday life and customs, both with regard to the ingredients for the recipes, the preparation methods and their respective tools (REVEL, 1996). The historical and anthropological knowledge of food production activities among Brazilian indigenous allows to highlight the crucial importance of the derivatives of manioc in their daily life, their life and their hospitality, which seeks to describe in this article; at the same time, it is revealed the existence of a real technological production system, the culinary system of manioc. It has been analyzed here in four stages: the relation to the ingredient or Raw Materials, manioc physical point of view; the second, with regard to the explanation of its origin and its social practice or their Culture; the third, which refers to the Technical and their uses, ranging from planting to obtain the products of the System; these three moments, methodologically informed by anthropology and history, preceding the fourth time in a formal analysis of the content of a historical work of art it emphasizes the importance of this root in the life and culture of the indigenous peoples in Brazil land.
\end{abstract}

Keywords: Manioc culture; Culinary system; By-products of manioc; indigenous culture.

\footnotetext{
* Este o artigo foi retirado da dissertação de mestrado de Marilia Malzoni Marchi, bolsista Capes.

' Doutor em História pela Universidade de São Paulo (USP), Brasil. E-mail: almaranhaz@terra.com.br.

${ }^{2}$ Doutora em História pela Pontifícia Universidade Católica de São Paulo (PUC-SP), Brasil. Professora da Universidade Anhembi Morumbi. E-mail bseniab@terra.com.br.

${ }^{3}$ Mestre em Hospitalidade pela Universidade Anhembi Morumbi, Brasil. Professora da Universidade Presbiteriana Mackenzie. E-mail: mariliamalzoni@ terra.com.br
} 


\section{Introdução}

Chamar, como faz Câmara Cascudo, a mandioca de "Rainha do Brasil" pode ter ummérito poético e umpoder de síntese antropológico, mas a ênfase em homenagear a tão brasileira euforbiácea não tem nada de novo, pois, desde o século XVI, a maioria dos que escreveram sobre a vida no Brasil teceram comentários airosos sobre ela $\mathrm{e}$, principalmente, sobre sua farinha e seus beijus, repetindo o entusiasmo de Brandônio em Diálogos das Grandezas do Brasil: "Pois essa farinha é um excelente mantimento, e tal que se lhe pode atribuir meritamente o segundo lugar depois do trigo, com exceder a todos os demais mantimentos" (apud CASCUDO, 1983, p. 91)

Compreende-se que sistema culinário é um conceito que reúne os itens constitutivos da alimentação, incluindo a transformação dos produtos e seus universos simbólicos. Assim, os modos de fazer, os lugares, as celebrações e as formas de expressão são partes integrantes desse sistema, que revelam maneiras de ser e de agir de grupos determinados(NOGUEIRA PINTO, 2006). Para Cascudo (1983), os sistemas culinários são conjuntos de práticas e representações, que unem as pessoas à sociedade e ao universo e identificam a posição e o comportamento das pessoas na totalidade. Operam a transformação simbólica da natureza à cultura, da fome ao paladar, do alimento à comida e da comida às refeições. A transformação dos produtos da natureza em comida opera a passagem do natural ao cultural: neste momento, o elemento deixa de ser considerado em si mesmo e passa a fazer parte de um sistema culinário.

Tendo isso em vista, neste artigo, objetiva-se descrever e analisar o sistema culinário da mandioca, em especial sua farinha, no quadro da maioria das culturas indígenas em território brasileiro. Acima de tudo, o artigo discorre sobreos métodos e as técnicas de pre- paro desses derivados, procurando mostrar como tais procedimentos constituem um sistema culinário que assegura eficiência na produção desses alimentos tanto para a sobrevivência das populações indígenas quanto para suas práticas comunitárias e de reciprocidade, sendo, portanto, um elemento central de suas culturas.

Quando Cascudo (1983, p.106) assevera que "a farinha é a camada primitiva, o basalto fundamental na alimentação brasileira", ele está se referindo também à viabilidade do contato entre o índio e o branco, em que este último, qualquer que fosse sua procedência, podia se alimentar de maneira satisfatória com os amidos da mandioca, os quais a primeira reciprocidade dos povos indígenasno Brasil fazia questão de oferecer:

Gastão Cruls contava-me da 'emoção' com que recebera de uma velha pianocoto, subindo o rio Paru, com Rondon rumando a cordilheira Tumucumaque, em 1928, um pedaço de beiju. Farinha de guerra - acrescenta Cascudo - mais seca, grossa e resistente, e os beijus viajavam nos navios de volta a Portugal a roda de 1584, (segundo Gabriel Soares de Souza): ...e os navios que vêm do Brasil para estes reinos, não têm outro remédio de matalotagem para se sustentar a gente até Portugal, senão o da farinha de guerra (CASCUDO, 1983, p. 92).

\section{Referencial e método}

Para aprofundar a análise do sistema culinário da mandioca, além de toda a referência historiográfica e antropológica utilizada como bibliografia para este artigo, usa-se aqui uma técnica de análise desenvolvida a partir de estudos de Food Design, mediante a análise detalhada de uma representação pictórica relativa à prática indígena. Para representar este sistema, foi escolhida a aquarela de Hercule Florence ${ }^{1}$, Maloca Apiacás sobre Rio Arinos, obra pintada 
em 1828, quando da passagem do naturalista pelo estado do Mato Grosso a bordo da Expedição Langsdorff; por seu rigor científico e grande lirismo, conferido pelo traço puro e pelas cores discretas. Nessa obra, a claridade e o calor do lugar são sugeridos, acrescentam-se os corpos nus dos indígenas, integrados e à vontade, ao mesmo tempo em que a escolha das figuras e a composição revelam papeis e práticas sociais.

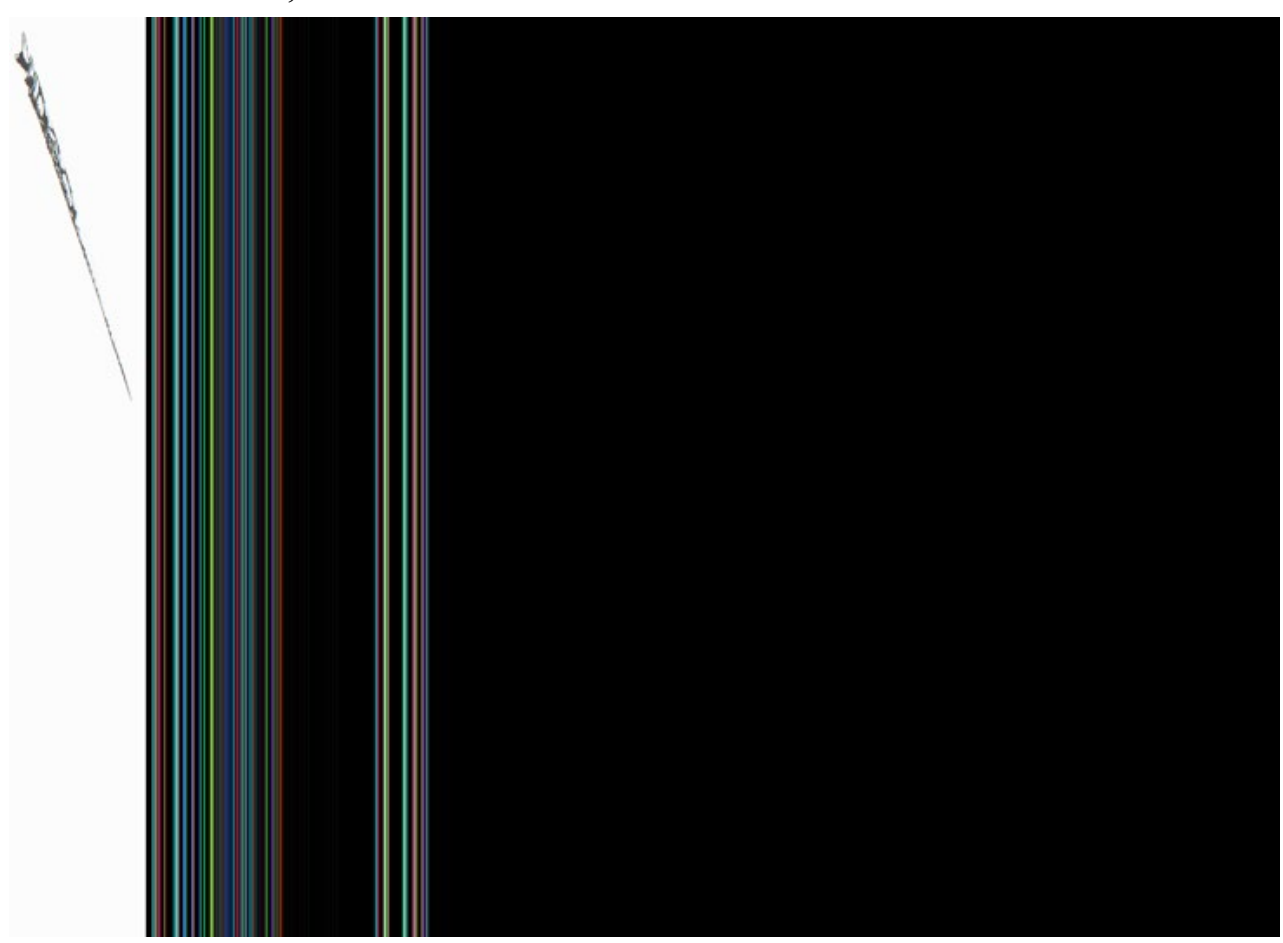

Figura 1 - Aquarela Apiacás

Fonte: Florence (1828 apud CATARINO; FERREIRA, 2009, p. 405).

Essa obra se encontra hoje na Academia de Ciências da Rússia, em Moscou. A atitude metodológica de análise aqui adotada se inspira no fato de que a obra de arte oferece um testemunho direto do mundo que a rodeou, em outra época. As imagens têm permanência na cultura, pois elas encarnam os modos de ver do pintor por meiodas marcas que este deixa sobre a tela. Ademais,na era da reprodução mecânica de imagens, o significado dos quadros não está mais ligado apenas a eles, uma vez que é transmissível, podendotransformar-se em informação. A reprodução permite que a imagem seja utilizada para fins diversos. É possível, por exemplo, usar o recurso do zoom e focalizar uma parte do quadro, transfor- mando o significado da leitura, além de realizar uma série de movimentos analíticos, seguindo também os ensinamentos de John Berger (2001).

Pode-se desenvolver toda uma análise da imagem escolhida como expressão pictórica significativa, pois Florence tem a característica de sempre trabalhar com rigor documental quando retrata a natureza, as diferentes nações indígenas, os costumes, os logradouros e as edificações. Não se deixa levar pela imagem rousseauniana do "bom selvagem", não monta nem idealiza a paisagem, usa o traço puro e a cor discreta para retratar o mundo tal como se apresenta em sua implantação espacial e natural: suas imagens são realistas. Mas, ao mesmo tempo, são imagens cuidado- 
samente construídas segundo as regras da perspectiva tradicional, são simples e sofisticadas e revelam a essência do assunto (KOSSOY, 2004).

Antes desta análise, porém, o presente artigo apresenta os elementos que a história e a arqueologia informam sobre o sistema de trabalho com a mandiocae seus derivados.

A origem e domesticação da mandioca (Manihotesculenta Crantz) são ainda controversas, existindo duas hipóteses principais a esse respeito. A primeira é de que a mandioca não tenha existido em estado selvagem, de modo que seria um híbrido resultante do cruzamento com outras espécies, apartir de mais de um centro de domesticação na Américas Central e do Sul. Os estudos de Anna Roosevelt (1990) sobre a caverna de Pedra Pintada apresentam os povos pioneiros da Amazônia brasileira como caçadores, coletores e responsáveis pela diversidade biológica da floresta. Estas descobertas foram ao encontro de conceitos desenvolvidos por vários outros pesquisadores, como Donald Lathrap, que, em seu livro $O$ Alto Amazonas, de 1970, descreve aquela região como um centro que disseminou, por meiodas migrações de sua população, toda uma cultura, que incluía o sistema produtivo da mandioca amarga e a cerâmica. A segunda hipótese consistena existência de um ancestral selvagem no cerrado brasileiro, ideia desenvolvida pelo etnólogo alemão Karl von denSteinen, em visita feita ao Xingu entre 1887 e 1888 e descrita na obra Entre os Povos do Brasil Central. Apesar disso, sabe-se que todas as espécies de mandiocasão originárias dos trópicos do Novo Mundo. Ao todo, são conhecidas 98 espécies, das quais 80 são sul-americanas (EMBRAPA, 2005).

A mandioca foi classificada pela primeira vez em 1691, na Historia Plantarum Universalis, de Johannes Bauhin, que estudou material colhido por André Thevet no Brasil e que, em homenagem a este, nomeou a raiz de Manihottheve- ti. Em 1766, Johann Crantz descreve a euforbiácea e publica o primeiro nome válido para a cultura de $M$. esculentasendo esculento algo que é bom para comer (EMBRAPA, 2005).

Suas raízes tuberosas são ricas em fécula. $\mathrm{O}$ caule adulto varia de uma três metros, e suas folhas são chamadas de maniva, das quais se faz um prato tradicional, a maniçoba. No Brasil, há duas espécies dominantes: a mandioca brava e a doce. A brava, localizada principalmente no nordeste brasileiro, possui ácido prússico venenoso, o qual deve ser extraído, pois pode causar intoxicação grave. É utilizada para fabrico de tucupi, cauim e farinhas diversas (SILVA, 2001). Já a mandioca doce, chamada de macaxeira no norte e de aipim no sul do país, é comida cozida, sendo utilizada também para fabrico de farinha fresca e do cauim (CASCUDO, 1988).

Borges Schmidt conceitua a terra boa para o plantio da mandioca como a dos "3ff": fofa, fresca, fértil. Como a principal parte utilizadase encontra nas raízes, o solo deve ceder ao crescimento, sendo propícios solos arenosos e bem revolvidos. São adequadas, também, as terras de matas recém-derrubadas e inclusive solos pobres, desde que tenham potássio, elemento importante para a formação do amido (PEREIRA, 1974).

\section{A cultura da mandioca: mitos e ri- tos do convívio social}

Fazem farinha de duas espécies: uma muito cozida e dura [...] outra menos cozida e mais tenra [...] Os Tupinambás, tanto os homens quanto as mulheres, acostumados desde a infância a comê-la seca em lugar do pão, tomando-a com os quatro dedos na vasilha de barro ou em qualquer outro recipiente e a atiram, mesmo de longe, com tal destreza na boca que não perdem um só farelo (LÉRY, 1557 apud ZENON, 2000, p. 131).

Em abril de 1500, os portugueses chegaram àcosta brasileira, fizeram con- 
tato com os povos indígenas no Brasil e, quando foram pela primeira vez em uma maloca, constataram que havia muitos inhames, tubérculos já conhecidos da costa africana, como consta na carta de Pero Vaz de Caminha. Em 1573, Pedro de Magalhães Gandavo informa que: "o que lá se come em lugar de pão é farinha de pau. Esta se faz da raiz duma planta que se chama mandioca, a qual é como um inhame" (CASCUDO, 1983, p. 89). O inhame foi trazido para o Brasil no século XVI, de Cabo Verde, Ilha de São Tomé. Portanto o inhame citado na carta era, sem dúvida, a raiz da mandioca(CASCUDO, 1983).

Os povos indígenas no Brasil tinham grande conhecimento sobre a mandioca: já a haviam selecionado e domesticado, pois eram conscientes de sua toxidade, e também sabiam tirar proveito de suas características e sua versatilidade (EMBRAPA, 2005). A cultura da mandioca foi amplamente registrada pelos viajantes que passaram pelo Brasil entre os séculos XVI e XIX. Eles expõem, discutem e registram minúcias do preparo das farinhas e dos beijus, que eram os dois elementos bási$\cos$ da alimentação da época. A farinha acompanhava tudo, da carne à fruta; e os beijus eram boa provisão para a caça, a pesca e as guerras.

Para o indígena a farinha seria a uí -pon, uí- puba, farinha puba, amolecida pela infusão, farinha d'água, e a uí-atã, farinha de guerra, seca, dura, resistente, comum. Feita de mandioca crua, raspada e espremida a mão ou no cilíndrico tipiti, a prensa de palha contráctil, tecida e sensível (CASCUDO, 1983, p.109).

Também produziam tucupi, tapioca, goma e bebidas como o cauim, a catimpuera, a caiçuma, além de comer as folhas/maniçoba. Essa dieta era completada com grande fartura de frutos, mel, castanhas, caça e pesca. Além disso, coletavam espécies vegetais, sementes, raízes, folhas ou cascas para produção de remédios e cultivavam feijão, mandioca, milho, jerimum e batata doce em volta da aldeia. Os utensílios, fossemdomésticos, rituais, agrícolas, de caça ou de pesca, eram feitos de palha, madeira, argila, cipó, pedra, osso e dente de animais e o que mais a natureza lhes provesse.

A farinha de guerra logo se tornou moeda de troca entre os índios, os africanos e os portugueses, que a exportaram para a África. Exportaram não só a farinha, mas também toda a cultura da mandioca, seu cultivo e a preparação das farinhas e dos bolos. Desde o início, a mandioca foi incorporada à dieta por dar base e sustância às carnes obtidas; um pouco mais tarde, os bandeirantes deixavam no caminho um grupo plantando mandioca e fazendo farinha para alimentar a todos. Nesse sentido, a mandioca foi responsável pela viabilização da colonização.

Nas culturas indígenas, ela já tinha um carácter mítico - existem várias lendas sobre sua origem coletadas pelos viajantes do século XVI ao XIX. Tamanha era sua importância para a sobrevivência dos povos indígenas portugueses no Brasil que era considerada uma espécie de dádiva divina (EMBRAPA, 2005).

No período colonial, foi batizada pelo Padre José de Anchieta com o cognome de pão da terra (PEREIRA, 1974). Contudo, o nome cotidianamente consagrado é mandioca, que vem do termo tupi manioca e que quer dizer casa de Maní. Muitos subprodutos também mantiveram o nome que recebiamna língua tupi: beiju, carimã, tapioca, manipuera, tucupi e maniçoba (CASCUDO, 1983).

\section{Cultura: mitos indígenas da man- dioca e da farinha e a Casa da Farinha}

Existem muitas versões do mito da mandiocano Brasil. Uma delas é a dos Tenetehara, grupo pertencente à família tupi-guarani, que serve como modelo ainúmeros relatos sobre o mesmo 
tema. Esse mito é sobre uma heroína, Maíra, que trouxe a sabedoria da agricultura e depois se foi. Outra versão é a de nações tupi da Amazônia, que também é usada como modelo para variações deste tema, sendo mais popular contemporaneamente:

Em tempos idos, apareceu grávida a filha dum chefe selvagem, que residia nas imediações do lugar que está hoje a cidade de Santarém. O chefe quis punir no autor da desonra de sua filha a ofensa que sofrera seu orgulho e, para saber quem era, empregou debalde rogos, ameaças e por fim castigos severos. Tanto diante dos rogos como diante dos castigos a moça permaneceu inflexível, dizendo que nunca tinha tido relação com homem algum. O chefe tinha deliberado matá-la, quando lhe apareceu em sonho um homem branco, que lhe disse que não matasse a moça, porque ela efetivamente era inocente, e não tinha tido relação com homem. Passados nove meses, ela deu a luz a uma menina lindíssima e branca, causando este último fato a surpresa não só da tribo como das nações vizinhas, que vieram visitar a criança, para ver aquela nova e desconhecida raça. A criança que teve o nome de Mani e que andava e falava precocemente, morreu ao cabo de um ano, sem ter adoecido e sem dar mostras de dor. Foi ela enterrada dentro da própria casa, descobrindose e regando-se diariamente a sepultura, segundo o costume do povo. Ao cabo de algum tempo, brotou da cova uma planta que, por ser inteiramente desconhecida, deixaram de arrancar. Cresceu, floresceu e deu frutos. Os pássaros que comeram os frutos e se embriagaram, e este fenômeno, desconhecido dos índios, aumentou-lhes a superstição pela planta. A terra afinal fendeu-se, cavaram-na e julgaram reconhecer no fruto que encontraram o corpo de Mani. Comeram-no e assim aprenderam a usar a mandioca (MAGALHÃES, 1876, p. 134-135 apud CASCUDO, 1988, p. 65).
Essa criança divina é portadora de mudanças, mediadora da fertilidade; ela própria dá sua vida em troca do conhecimento da agricultura, sacrificando-se ao se transformar na raiz. Tal mito ilustra a posição da mulher na cultura indígena, que, por meio do seu sacrifício, transforma a realidade. Toda a ordem social se transformou com o conhecimento da mandioca e da agricultura e com a criação de seus produtos.

O surgimento da técnica de transformação da mandioca em farinha também possui mitos, como o do Deus Tupã que a concede aos homens. Nestes mitos, também são encontradas as tarefas da prática atribuídas às mulheres (SILVA, 2001).

Todas as técnicas relativas à cultura da mandioca, desde a preparação do solo até acolheita, eram desempenhadas por todo o grupo, de forma coletiva. A divisão dos produtos resultantes destas práticas também era feita dentro de uma reciprocidade de vizinhança. E isso era tão importante para a sobrevivência, que nos mitos e nas lendas indígenas, que são épicos, eram primeiro narradas guerras e grandes caçadas, para que então o grupo se reunisse novamente junto a uma roça de mandioca. "A mandioca aparece com frequência como a causa do retorno à aldeia e da reunião do grupo. Após longos períodos de caça, voltava-se para "fazer farinha"' (FAUSTO, 2001 apud EMBRAPA, 2005, p. 79).

Existia a produção de farinha, tanto dentro como fora da casa comunal, em construção aberta, sem paredes, onde se encontrava um grande forno de barro e se torrava a farinha (SCHMIDT, 1958). Esta construção foi chamada de Casa da Farinha, constituindo-se em um núcleo simbólico (NOGUEIRA; WALDECK, 2006). Como as práticas eram demoradas e necessitavam de muitas pessoas, chamavam-se parentes e vizinhos e estes conviviam de forma intensa, de modo que, durante a realização de alguma tarefa, por exemplo, muitas vezes se sentavam em círculos 
e conversavam sobre temas da vida diária (EMBRAPA, 2005). Não havia uma divisão da vida em lazer e trabalho, e os indivíduos estavam integrados ao meio. O sistema culinário da mandioca, depois do cultivo em roças chamadas "de coivara", ocorria em etapas: as raízes da mandioca brava eram arrancadas da terra pelas mulheres, colocadas em cestos, imersas em água para soltarem a casca, em um processo conhecido como puba ou mandiyvunga; então eram descascadas, raladas e peneiradas com água para que, por meio de pressão manual, parte do líquido venenoso pudesse ser retirado; depois era colocada no tipiti, quando o resto do líquido saía, originando um sumo do qual se fazia o tucupi (SILVA, 2001).

\section{Técnicas e artefatos}

Depois desse sumo ser retirado, a substância restantetransforma-se em uma massa chamada de goma ou polvilho, com a qual se fazem também a tapioca e os beijus. Os beijus eram postos ao fogo para torrarem e se tornarem mais secos, sendo de fácil conservação e prático manuseio, o verdadeiro "pão" rotineiro do indígena. Outra possibilidade era fazer a chamada de farinha de guerra, porque os índios a levavam quando iam à guerra. Muitas vezes, também era misturada com pedaços de caças ou peixes, originando a paçoca.

Depois de torrada em largos tachos de cerâmica, a farinha era armazenada em grandes cestos chamados paneiros, com ou sem asa, feitos de palha, cipó ou vime. Esses cestos eram forrados internamente por folhas, normalmente de palmeira, que impediam a entrada de ar, água e luz, garantindo a conservação por longo tempo (SILVA, 2001).

A partir da mandioca também se faziam várias bebidas, como o caxirie o tarubá feitos do beiju-açu mofado. A catimpuera era temperada com mel e água, e a caiçuma era temperada com gengibre e mel, ambas feitas a partir da macaxeira cozida e amassada. Outra possibilidade era o cauim: após a mandioca ser cozida em água fervente, era mastigada pelas mulheres, colocadas com água novamente para ferver e então colocadas para fermentar em potes próprios que se encontram enterrados no chão na altura da metade (EMBRAPA, 2005). O produto cauim era de teor alcoólico mais elevado, sendo largamente consumido nas festas rituais, em que a comunidade recebia hospitaleiramente a vizinhança e todos dançavam por muitas horas.

Os tupinambás e outras nações do ramo tupi-guarani preparavam a farinha dentro da própria habitação, mas comumente se acendia a fogueira nas ocaras, pátio das tabas, principalmente para moquear o produto das grandes caçadas ou para fabricar bebidas fermentadas. Os bacairis e os curutus tinham suas cozinhas no centro de suas habitações, em torno de um poste principal, sobre o qual se encontrava uma abertura na cobertura. Existia a produção de farinha, tanto dentro como fora da casa, em construção aberta, sem paredes, onde se encontrava um grande forno de barro e se torrava a farinha (SCHMIDT, 1958).

Os utensílios culinários, por sua vez, ficavam tanto dentro da casa comunal quanto na Casa de Farinha. Estes utensílios pendiam do teto e das paredes, encontravam-se espalhados pelo chão ou ficavam suspensos por caibros e esteios.

Para o sucesso destas operações, foi necessário inventar ao longo dos tempos toda uma tecnologia: amplos e pesados ralos, recipientes de argila e cerâmica, vasilhames de palha e casca de cueira, cestas, peneiras adornadas com figuras zoomorfas e desenhos geométricos e um aparelho chamado tipiti,notável recipiente feito de alavancas de palha e capaz de prensar a massa da mandioca por meio da pressão manual. $\mathrm{Ou}$ seja, foi necessário um conjunto variado e eficiente de artefatos, mais a técnica da produção dos vários tipos de 


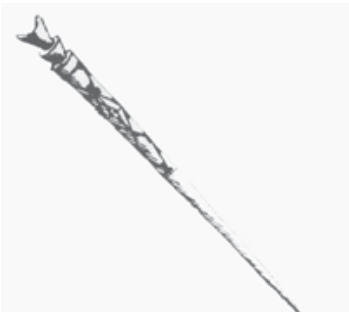

Figura 2 - Pau de cavouco dos índios Kamayurá. Fonte: Ribeiro (1988, p. 268).

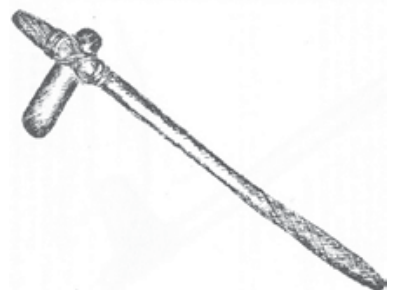

Figura 3 - Machado de pedra dos índios Borôros. Fonte: Ribeiro (1988, p. 266).

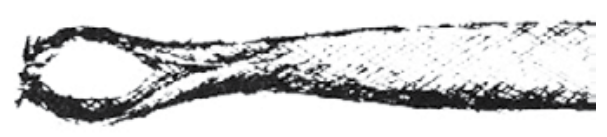

Figura 4 - Aturádos índios Makú Fonte: Ribeiro (1988, p. 43).

farinha, beijus, etc. (PEREIRA, 1974).

O processo da farinha começava com a raspagem para a remoção da casca, em que se usava uma concha ou casca de ostra, como resume Artur Ramos: "Os índios descascavam os tubérculos, com valvas de ostras ou com uma peça de madeira na qual estavam encaixadas lascas de pedra e às vezes arestas ósseas de peixes" (apud SCHMIDT, 1958, p.51).

Para o plantio e a colheita da mandioca, os povos indígenas no Brasil utilizavam paus de madeira, talhados em pontas e com adornos; e também machadinhas, lascas de pedra presas em cabos de madeira. As raízes eram colocadas em cestos chamados turra, às vezes presos à testa por meio de faixas (EMBRAPA, 2005).

Podiam ou não secar as raízes descascadas. Quando o faziam, secavamnas no moquém, que é uma grelha, de ripas espaçadas e atravessadas, de madeira verde, mantida sobre estacas do mesmo material, em número de quatro, com forquilhas naextremidade. No moquém, era feita uma fogueira, mais de brasas do que de achas ou gravetos, que produzem labaredas, para nele secarem com a exposição ao calor moderado carnes de peixes, pássaros ou quadrúpedes, forma de conservar a carne por muito tempo (PEREIRA, 1974). A etapa seguinte era a ralagem. Hans Staden (2014, p. 142) conta que os tupinambás de Ubatuba "trituram sobre pedra as raízes totalmente, em pequenos gumos, etc." e, para reduzir a pó, utilizavam um pilão de madeira.

Com o tempo, passaram a utilizar ralos ou caititus de madeira com espinhos de palmeira, com tamanho entre $115 \mathrm{~cm}$ de comprimento e $80 \mathrm{~cm}$ de largura. Posteriormente, desenvolveram raladores com pedrinhas ou dentes de animais engastados, operação que demanda técnica especial.

$\mathrm{O}$ produto da ralagem, a massa da mandioca, era peneirada com água, em um tupé, esteira de talas de arumã, sobre uma panela de barro. Depois, a massa era colocada no tipiti e prensada.

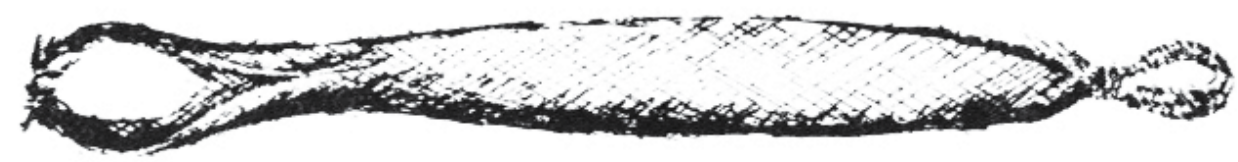

Figura 5 - Tipiti dos índios Tukúna Fonte: Ribeiro (1988, p. 57). 
O cientista baiano Dr. Alfredo da Mata, em seu Vocabulário da Região Amazônica, apresenta o verbete tipiti:

Tipiti-(Reg.) - Aparelho de compressão e expressão, fabricado de talas de aruman, em feitio tubular e extremidades afuniladas, a terminarem em alças. Presa a uma delas, em certa altura, colocada a substância dentro do tubo, procede-se à expressão, distendendo-se, gradual e fortemente na laça inferior empregada a força manual ou pesos em série crescente. Ótimo para o preparo da massa úmida da mandioca, da farinha branca e a de suruhi. Muito usado em misteres domésticos e pequenas indústrias. Amazônia. Do tupi tipi=expremer, ti+ sumo, líquido (PEREIRA, 1974, p. 163).

A massa que saía do tipiti era peneirada em urupemas, originando, conforme a espessura da peneira e a quantidade de vezes que era peneirada, uma variedade de farinha diferente. Os povos indígenas que habitavam os vales do Rio Negro e Rio Branco tinham muita habilidade e gosto artístico - com as fibras das espécies vegetais, produziam peças admiráveis para uso doméstico, abanos, peneiras e charões, os quais eram empregados para acomodar frutas e beijus. A originalidade e beleza consistem no trançado de sua parte côncava ou na superfície quadrangular da peneira, em que há uma admirável combinação de figuras geométricas.

Tal massa também podia ser triturada, antes ou depois da torra, em pilões de madeira. "... a mesma mandiopuba, torrada ao fogo, é chamada de Kaaarima, e depois de moída em pilão de madeira toma o nome de Kaarimaciu" (NIEUHOF,1640/1649 apud ZENON, p. 135, 2000).

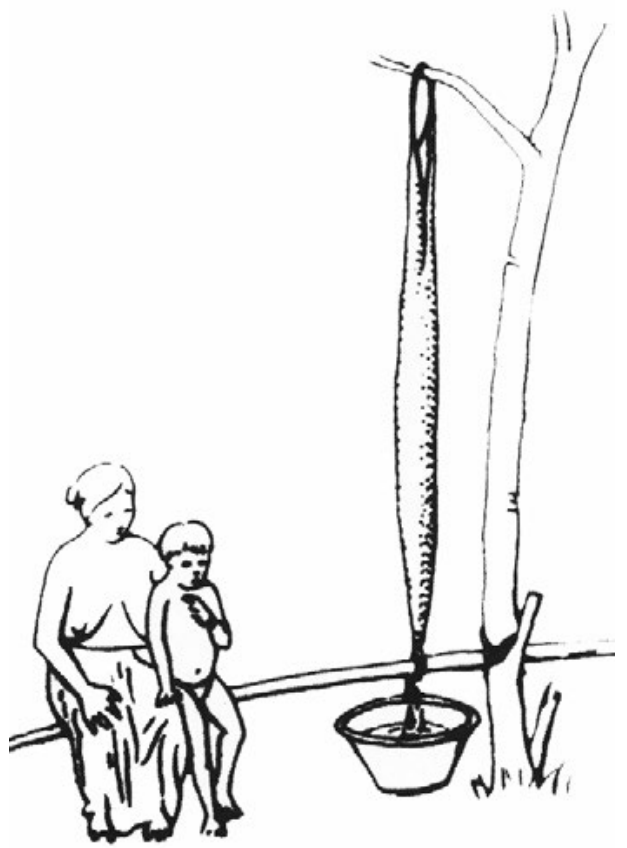

Figura 6 - Desenho de processamento da mandioca para fazer farinha

Fonte: Nimuendaju (apud MEIRELLES FILHO, 2011, p. 87).

Em seguida, a massa ia ao fogo em toda uma variedade de fornos. Lery discorre sobre os fornos usados pelos tupinambás: "Para preparar esta farinha usam as mulheres brasileiras grandes e amplas frigideiras de barro, com capacidade de mais de um alqueire e que elas mesmas fabricam com muito jeito, etc." (apud PEREIRA, 1974, p. 60). Também eram utilizados rodos, pás e cuias para espalhar a massa e, de vez em quando, atirá-la ao ar para arejar.

Os utensílios de cerâmica, cada vez mais utilizados, ganharam muitas formas, indicadas pelo modo de preparar o alimento e pelas experiências cotidianas. Sua riqueza na cultura indígena, particularmente na Ilha de Marajó, é de tal ordem que não se pode tratá-la nos limites deste artigo, sendo preciso remeter o leitor a trabalhos como o de Heloisa Alberto Torres, intitulado Conferência sobre Cerâmica Marajoara (PEREIRA, 1974). 
Também eram utilizados como vasilhas os frutos da árvore cueira, as cuias. Segundo Paul Le Cointe, para fazer a cuia, retira-se a polpa espessa de forma globular, atingindo mais de $25 \mathrm{~cm}$ de diâmetro. Então, a casca, de regular espessura e dureza, é partida ao meio e posta para secar. Depois, seu interior é revestido com a resina do cumatê misturada à urina, que, quando seca, torna-se preta e brilhante. A cuiapitinga é revestida internamente, e a cuia-pininga é pintada por dentro e por fora (PEREIRA, 1974).

\section{Os produtos e seu uso}

$\mathrm{O}$ primeiro produto utilizado pelos povos indígenas no Brasil, proveniente da mandioca, era suas folhas. Com elas se prepara um prato chamado maniçoba, obtido por meio da cocção, durante sete dias, das folhas verdes da mandioca mansa, misturada a muitas variedades de carnes e condimentos (MARANHÃO, 2010).

Já o primeiro produto resultante do processo de obtenção das farinhas, era o sumo da massa de mandioca a fécula ou manipuera para os índios. Dela se faziam o arubé e o tucupi, dois molhos de gosto acentuado, usados para acompanhar carnes e peixes. No Fichário Ernani de Silva Bruno, editado pelo Museu da Casa Brasileira, há alguns verbetes acerca destes molhos:

Arubé - "Para o peixe usávamos um molho, em forma de pasta amarela, inteiramente novo para mim, chamado arubé, feito do suco venenoso da raiz da mandioca, fervido antes da precipitação do polvilho ou tapioca e temperado com pimenta malagueta. É conservado em vasilhas de pedra durante algumas semanas, antes de ser usado, e é apetitoso condimento para o peixe" (ZENON, 2000, p. 216).

Tucupi- "O tucupi, outro molho feito também do suco da mandioca, é muito mais comum no interior da Amazônia que o arubé. É preparado pelo aquecimento ou cocção do líquido puro, depois da separação da tapioca. Durante vários dias a fio, e temperado com pimenta e pequenos peixes; quando velho, tem gosto de extrato de anchovas. Geralmente é líquido, mas os Jurí e Miranha do Jarapurá, preparam-no em forma de uma pasta negra por processo que não consegui aprender; é então chamado tucupí-pixuma ou tucupí preto" (ZENON, 2000, p. 343).

Quando o sumo (ou amanipuera) era aquecido em água fervente, originava-se a goma, que tinha usos medicinais e culinários, como o tacacá, um caldo com camarões secos. O sumo também podia ser colocado para decantação e, ainda úmido, sobre uma chapa quente, sendo chamado de tapioca, uma espécie de panqueca, muito digestiva, composta por grânulos de diversos tamanhos, considerada um alimento dos deuses. Quando se permitia que a decantação chegasse ao final, o produto era chamado de polvilho, com o qual se fazia farinha de tapioca e de carimã, as quais davam origem a pães, bolos e biscoitos finos (MARANHÃO, 2010).

Mario Ypiranga Monteiro, historiador, folclorista e pesquisador do Instituto Nacional de Pesquisas da Amazônia (INPA), em seu estudo intitulado Alimentos Preparados à Base de Mandioca, discorre sobre os beijus:

Espécie de bolo chato, com forma mais comum de disco, variando para meia lua, losangular. É depois da farinha, o alimento mais decantado pelos cronistas de todas as épocas, que, todavia nem sempre distinguiram as castas. Não só no Brasil mas em muitas regiões da América pré-colombiana era ele conhecido. É confeccionado com a massa da mandioca puba e que foi ralada. Das várias castas e formas conhecidas e referidas damos a relação e a receita, e em apêndice, duas fotos (MONTEIRO, 1963, p. 42 ).

E chega a apontar uma lista de nada menos do que 14 tipos de beijus, 
aos quais ainda se poderia acrescentar outra lista de Barbosa Rodrigues, em que este que apresenta mais cinco tipos.

Nas atividades comunitárias e nos momentos de reciprocidade da vizinhança, ou quando recebiam estrangeiros, os povos indígenas no Brasil consumiam esses produtos da mandioca com carnes de caça e frutas e se deleitavam bebendo o cauim alcoólico ou bebidas como a catimpuera, temperada com mel e água, e a caiçuma, temperada com gengibre e mel, obtidas por meio da macaxeira.

\section{Análise da imagem (representação)}

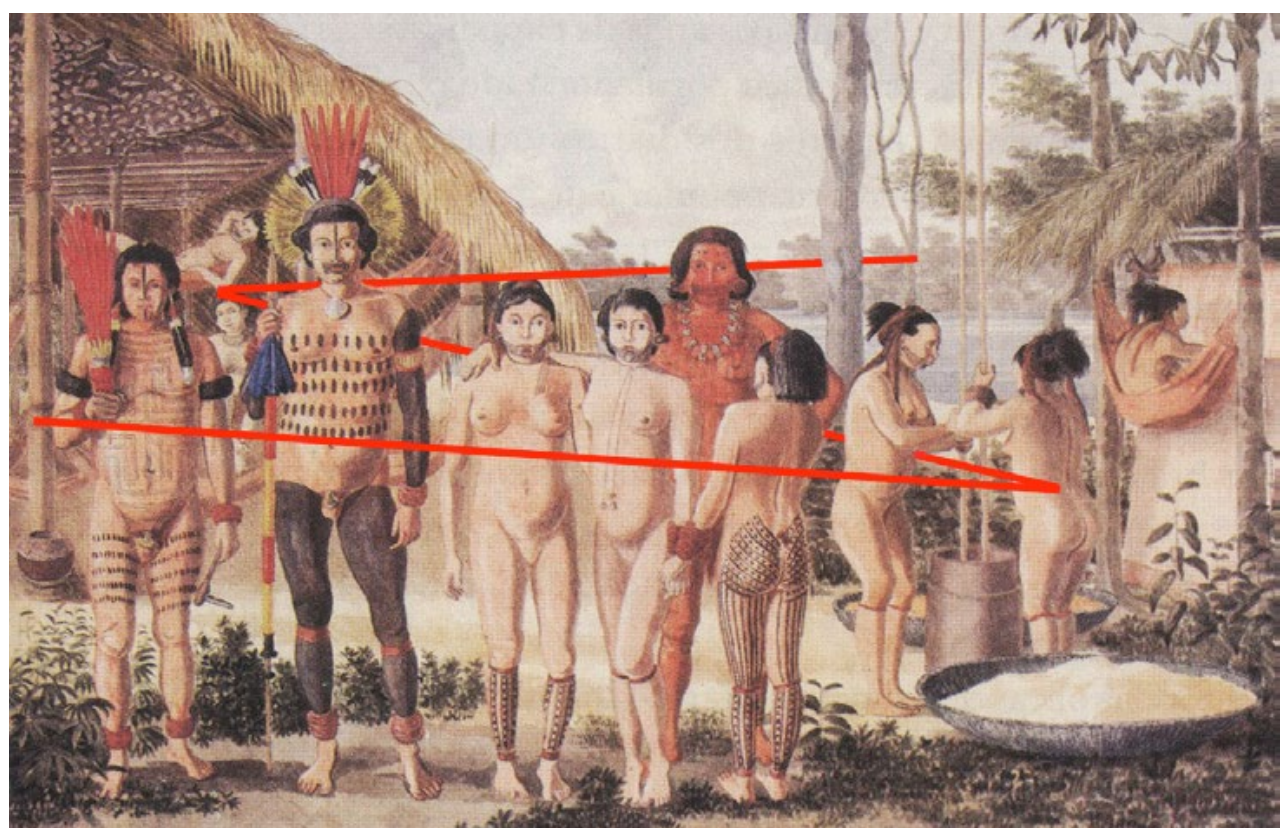

Figura 7 - Aquarela de Hercule Florence

Fonte: Florence (1828 apud CATARINO; FERREIRA, 2009, p. 405).

* Os traços vermelhos foram inseridos pelos autores deste artigo.

A obra de Hercules Florence foi construída com figuras humanas que constituem o primeiro e segundo planos; no terceiro, o de fundo, vê-se a paisagem do rio Arinos. Háuma colagem de imagens previamente estudadas, que foram reunidas aqui em uma composição determinada, para representar uma organização social. Representação que tem aqui um forte viés realista e naturalista: seu autor, além de manifestar sempre clara preocupação com a expressão objetiva do real nas artes plásticas, não contente com isso, chegou mais tarde a inventar pioneiramente a fotografia, como o recurso mais próximo possível da realidade.
Como mencionado, a imagem foi construída segundo as regras da perspectiva tradicional (KOSSOY, 2004). A perspectiva é a forma gráfica bidimensional que representa o modo tridimensional que vemos, uma ilusão convincente da realidade. Trata-se de um método que utiliza a linha para criar efeitos visuais especiais de nosso ambiente natural. Simula distância, massa, ponto de vista, ponto de fuga, linha do horizonte e nível do olho, elementos que são intensificados por meio da manipulação tonal, isto é, do jogo de claro e escuro. Fazem parte dos elementos visuais básicos o ponto, a linha, a forma, a direção, a cor, o tom, a textura, a 
escala, a proporção e o movimento. Os elementos visuais são manipulados em resposta direta ao objetivo da mensagem (DONDIS, 1997).

Para a análise, foi considerada, em primeiro lugar, toda a composição, sendo analisados alguns dos seus elementos visuais; e, em segundo lugar, a forma de análise apontada por Berger como aquela que usa o recurso do zoom e focaliza uma parte do quadro, transformando o significado da leitura.

Em primeiro plano, apartir da esquerda (leitura ocidental), há duas figuras de guerreiros, com suas mulheres atrás; no centro, o pajé com meninas, e, à direita, a farinha, tendo ao fundo duas índias pilando. Três grupos representam os principais aspectos que regem a vida: a guerra, a religião e o alimento. $\mathrm{O}$ quadro está simetricamente dividido em três. O que une as três partes é uma linha de composição (desenhada pelos autores em vermelho na gravura, em forma de zigue-zague, que começa à esquerda nos guerreiros em direção as índias que estão pilando, e vai destas para a maloca onde se veem outras duas índias, uma deitada e a outra sentada em redes, terminando em última linha para a paisagem do rio Arinos, ao fundo do quadro - o que gera um grande efeito de profundidade.

Ao analisar as massas, percebem-se, nas laterais de ambos os lados do quadro, malocas, que formam um espaço aberto ao fundo, e no centro, que faz fundo para a figura do pajé, o qual ganha, assim, destaque, por estar pintado de vermelho. As cores predominantes nos primeiro e segundo planos são os laranjas, as cores de pele e os verdes da vegetação, que aparecem escuros, o que lhes dá maior luminescência. Do lado direito, entra uma luz muito clara, que deixa a vegetação esmaecida, dando uma sensação de que a cena está na sombra e de que o fundo está na luz.

Os três grupos, além da linha de composição que os une, são autônomos, pois cada um compõe uma cena própria, conforme é possível verificar na Figura 8 , exposta a seguir.

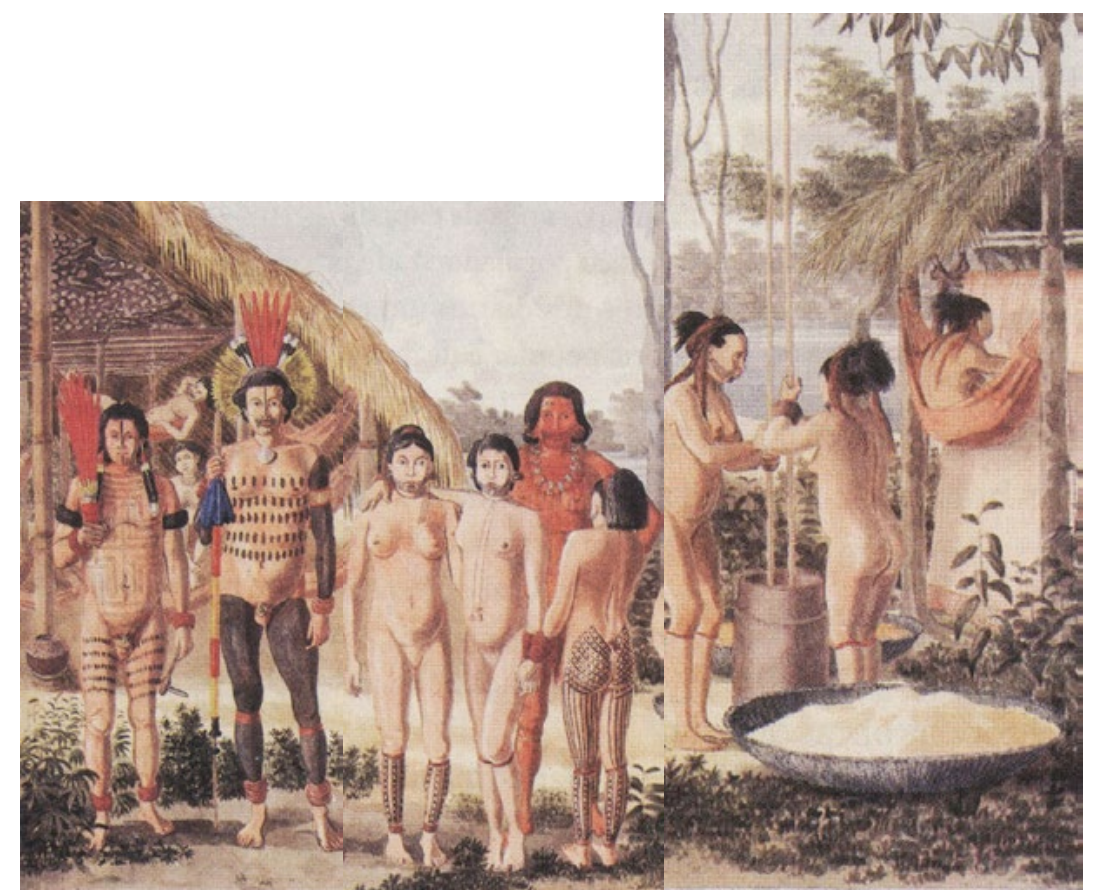

Figura 8 - Aquarela Maloca dos Apiacás sobre o Rio Arinos, Hercule Florence (1828), dividida em partes.

Fonte: Florence (1828 apud CATARINO; FERREIRA, 2009, p. 405). 
O grupo 1 é composto dedois guerreiros que estão perfeitamente ornamentados para algum tipo de rito ou para a própria guerra. Percebe-se claramente, por meio de sua estatura e dos ornamentos que usam, a hierarquia existente entre eles. O da direita é o chefe, sendo a figura mais alta de todo o quadro, pois possui um grande cocar de penas de pássaros coloridas: vermelhas, brancas, pretas e beges, lembrando a forma das aureolas dos santos, o que o faz ficar ainda maior. É a primeira figura que se destaca. Também veste um colar de concha, carrega uma lança adornada com penas azuis e possui pulseiras de penas nas extremidades do corpo, que está mais pintando de preto do que o da outra figura. A figura da esquerda, por sua vez, não possui cocar, mas um penteado especial, com os cabelos divididos em dois, enrolados por fios (brancos, pretos e vermelhos) e caindo de cada lado da cabeça; na mão, em vez de uma lança, possui uma espécie de abanador feito de penas vermelhas, e seu corpo está pintado de preto, possuindo pulseiras de penas vermelhas nas extremidades do corpo. Ao fundo, vê-se uma grande maloca com índias deitadas e sentadas em redes, criando uma relação com a figura dos guerreiros, de modo que parecem ser suas mulheres.

O grupo 2 é composto pelo pajé e por jovens índias. O pajé pode ser notado por meio da cor de sua pintura corporal, o vermelho, que cobre todo o seu corpo. Possui, ainda, um colar e dois brincos e está colocado no centro do quadro; portanto, sua posição e sua cor o denotam como uma figura importante no quadro. Está rodeado por jovens índias que possuem algumas pinturas corporais.

O grupo 3 é composto pelo alimento, no caso a farinha, que aparece em uma grande vasilha de barro que resplandece ao sol, assemelhando-se ao ouro. Essa vasilha foi colocada, inclusive para que tivesse destaque, sobre um pequeno pedestal, construído por meio- da elevação no terreno. Atrás dela, estão duas índias que pilam farinha e, ao lado, há mais uma grande vasilha com farinha, representando a abundância vivida pelos apiakás. A cena é ainda mais enfatizada por meio de linha vertical que se inicia com a árvore e continua com a índia que pila, terminando na grande vasilha de farinha, no primeiro plano.

\section{Considerações finais}

A farinha faz parte de toda uma estória, de uma atividade, que se desenvolve dentro da cena total do quadro. Trata-se de uma atividade que é mostrada em movimento - é o único grupo em movimento, os outros dois estão estáticos. É, portanto, dinâmica e também social: as mulheres realizam em grupo as tarefas para obtenção da farinha: plantio, coleta, moagem e cozimento. E com ela pronta fazem outros produtos, como os beijus e a paçoca.

$O$ fato de o quadro estar dividido em três partes iguais, em quesão representados os principais aspectos que regem a vida (a guerra, a religião e o alimento), atesta a importância da cultura da mandioca dentro do sistema alimentar dos povos indígenas no Brasil. Temos, portanto, uma composição montada de forma intencional para representar uma organização social, que tem os guerreiros como figuras sociais máximas e a produção do alimento e das farinhas como o seu segundo grande interesse. Sendo uma atividade que se desenvolve todo o tempo, pois alimentos são necessários em períodosde paz e de guerra, é representada em movimento: duas índias estão pilando a farinha.

Dessa forma, a escolha de uma obra de arte representativa das pesquisas e representações naturalistas, característica da verdadeira "descoberta do Brasil" que foi a produção de informações sobre nossa terra por viajantes estrangeiros durante o século XIX, vem realçar a presença da Manihotesculenta na alimentação, na vida cotidiana e na 
reciprocidade dos povos indígenas no Brasil. Essa presença é tanto mais eficaz quanto resultante de um sistema tecnológico de produção e preparo, o denominado sistema culinário da mandioca, que se constituiu em um dos centros básicos da cultura alimentar de nossa pré-história e que ajudou a construir a nossa história.

\section{Referências}

01. BERGER, J. Modos de Ver. Orig. 1972. Lisboa: Edições 70, 1999.

02. CASCUDO, L. da C. Dicionário do folclore brasileiro. São Paulo: Editora da Universidade de São Paulo, 1988.

03. 1898- História da alimentação no Brasil. Belo Horizonte: editora Itatiaia. São Paulo: Editora Universidade de São Paulo, 1983.

04. CATARINO, N. M.; FERREIRA, D. F. Um humanista nos trópicos: a singular trajetória de Hercule Florence no Brasil. In: VIDAL, Laurent; LUCA, Tania Regina de (Orgs.). Franceses no Brasil: séculos XIX-XX. São Paulo: Editora Unesp, 2009.

05. DONDIS, D. A. Sintaxe da Linguagem Visual. Tradução de Jefferson Luiz Camargo. 2. ed. São Paulo: Martins fontes, 1997.

06. EMBRAPA. Mandioca o pão do Brasil. Brasília: Embrapa, 2005.

07. GUERRA, S.J. W. N.;SILVA, R. da (Orgs.). Equipamentos. Fichário Ernani Silva Bruno.São Paulo: Museu da Casa Brasileira, 2000.

08. JUNG, C. G. O Homem e seus símbolos. Tradução de Maria Lucia Pinho. 1. ed. Rio de Janeiro: Editora Nova Fronteira, 1983.

09. KOSSOY, B. Hércules Florence, da imagem pictórica à imagem técnica: anos decisivos. Professor titular do departamento de Jornalismo e Edi- toração da escola de Comunicações e Artes da Universidade de São Paulo. Conferência apresentada no VII Colóquio Brasil-França de Ciências da Comunicação. 2004.

10. MARANHÃO, R.Mandioca, na História e no Pão.Revista Sabores, Gastronomia e História, Belo Horizonte, Ano V,p. 18-25, 2010.

11. Mandioca o Pão do Brasil. Brasília: Embrapa, 2005.

12. MEIRELLES, F. J. Grandes expedições à Amazônia Brasileira. São Paulo: Metalivros, 2011.

13. MONTEIRO, Mario Y. Alimentos preparados à base da mandioca. Revista Brasileira de Folclore, Rio de Janeiro, n* 5, p. 37-82, 1963.

14. NOGUEIRA, P. M. D.Sabores e Saberes da Casa de Maní: a mandioca nos sistemas culinários. Revista do Patrimônio Histórico e Artístico Nacional, Salvador, n. 32, p. 281-301, 2006

15. PEREIRA, N. Panorama da Alimentação Indígena. Rio de Janeiro: Livraria São José, 1974.

16. SILVA, P. P. Entre Tampas e Panelas: por uma Etnografia da Cozinha do Brasil. 2001.134 f.Dissertação (Mestrado em Antropologia Social) - Universidade de São Paulo. São Paulo, 2001.

17. REVEL, J.-F. Um banquete de palavras. São Paulo: Companhia das Letras, 1996.

18. RIBEIRO, B. G. Dicionário do artesanato indígena. Belo Horizonte: Editora da Universidade de São Paulo, 1988.

19. SCHMIDT, C. B. Lavoura Caiçara. Rio de Janeiro: Ministério da Agricultura, Serviço de Informação Agrícola, 1958.

20. STADEN, Hans. Duas viagens ao Brasil: Primeiros registros sobre o Brasil. Porto Alegre: L\&PM, 2014.

21. VALERI, R. Alimentação. Homo 
Domesticação/Cultura Material. Einaudi.Lisboa: Imprensa Nacional/Casa da Moeda, v. 6, 1989.

22. WALDECK, G.; NOGUEIRA, M. D.Mandioca: saberes e sabores da terra. Catálogo Exposição Museu de Folclore Edison Carneiro, Centro Nacional de Folclore e Cultura Popular. Rio de Janeiro: IPHAN, 2006.

23. ZENON, C. A. Alimentação. Fichário Ernani Silva Bruno.São Paulo: Museu da Casa Brasileira, 2000.

24.

Equipamentos. Fichário

Ernani Silva Bruno.São Paulo: Museu da Casa Brasileira, 2000. 